\title{
Influência da cobertura de resíduos de culturas nas fases da evaporação direta da água do solo ${ }^{1}$
}

\author{
Paulo S. L. Freitas ${ }^{2}$, Everardo C. Mantovani ${ }^{3}$, Gilberto C. Sediyama ${ }^{3}$ \& Luiz C. Costa ${ }^{3}$
}

\section{RESUMO}

No presente trabalho, analisou-se a influência dos resíduos de culturas do milho e do trigo nas fases de evaporação da água do solo para duas classes texturais. Os tratamentos constaram de três taxas de resíduo de culturas, 0, 50 e 100\% da matéria seca e de três demandas evaporativas. A taxa de evaporação da água do solo descoberto apresentou comportamento distinto para as três demandas evaporativas utilizadas. Para a demanda evaporativa de aproximadamente $3 \mathrm{~mm} \mathrm{~d}^{-1}$, o tratamento com solo descoberto permaneceu no primeiro estágio de evaporação, pelo período de 21 dias do experimento. O conceito U, estabelecido por Ritchie (1972) para definir o final do primeiro estágio, não foi observado para as demandas evaporativas de 5,2 e $3 \mathrm{~mm} \mathrm{~d}^{-1}$. Para essas demandas, o solo permaneceu no primeiro estágio de evaporação durante o período de coleta de dados de 21 dias. Para a taxa de resíduos de 100\% da matéria seca, para as culturas do milho e do trigo, a demanda evaporativa teve pequena influência na redução na evaporação da água do solo que, em média, variou de $28 \%$ da evaporação ocorrida no tratamento com solo descoberto, havendo diferença significativa entre as taxas de resíduo, mas não ocorreu diferença entre as duas classes de solo, para a lâmina d'água evaporada em 21 dias.

Palavras-chave: classes de solo, demanda evaporativa, estágio de evaporação

\section{Effects of surface mulches from crop residues on the direct soil water evaporation}

\begin{abstract}
The effects of surface mulches from corn and wheat crop residues on the direct soil water evaporation stages were analyzed for two soils of different textural classes. The treatments consisted of three rates of crop residues, 0,50 and $100 \%$ of the dry matter and three water evaporative demands. The bare soil water evaporation presented distinct behavior for the three tested water evaporative demands. For the water evaporative demand of nearly $3 \mathrm{~mm} \mathrm{~d}^{-1}$, the treatment with bare soil stayed in the first stage of evaporation rate, at least for the period of 21 days of the experiment. The concept $\mathrm{U}$ established by Ritchie (1972) to define the end of the first water evaporation stage, was not observed for the water evaporative demands of 5.2 and $3.0 \mathrm{~mm} \mathrm{~d}^{-1}$. For these demands, the soil stayed in the first evaporation stage during the data collection period of 21 days. For the residual rate of $100 \%$ of dry matter and for the corn and wheat cultivations, the evaporative demand had a modest influence in reducing the soil water evaporation, which on average varied $28 \%$ of the evaporation occurred in the treatment with bare soil, having significant difference among the residual rates, but did not occur differences between the two soil classes, for the water depth evaporated in 21 days.
\end{abstract}

Key words: evaporation, residues, evaporative demands, evaporation stage

1 Parte da Tese de Doutorado do primeiro autor

2 DAG, Universidade Estadual de Maringá, Av. Colombo, 5790, CEP 87020-900, Maringá, PR, Brasil. Fone: (44) 3261-4316 E-mail: pslfreitas@uem.br 3 DEA, Universidade Federal de Viçosa, Av. P.H. Rolfs s/n, CEP 36571-000, Vicosa, MG, Brasil. Fone: (31) 3899-2734 E-mail: everardo@ufv.br sediyama@ufv.br I.costa@ufv.br 


\section{INTRODUÇÃO}

A taxa de transferência de água do solo para a atmosfera através das plantas, pode ser limitada pelo solo, pela planta e pelas condições atmosféricas. Para os cultivos anuais, no início da fase de crescimento, quando o solo está parcialmente coberto pelo dossel da cultura, a evapotranspiração da cultura é dominada pela evaporação da água do solo. A evaporação direta da água do solo descoberto e úmido é influenciada, antes de tudo, pela energia disponível. Com o secamento da superfície do solo, a evaporação se torna dependente das propriedades hidráulicas do solo próximo à superfície (Ritchie, 1972).

A taxa de evaporação da água do solo pode ser agrupada em diferentes estágios. O primeiro estágio pode durar de um a três dias, conforme a magnitude da taxa de evaporação que, nesta fase, depende das condições atmosféricas externas, sendo esta de aproximadamente $90 \%$ da demanda evaporativa. A duração desse estágio é influenciada pela taxa de evaporação, pela profundidade do solo e pelas propriedades hidráulicas do solo. Durante o segundo estágio a superfície se torna seca e a evaporação ocorre abaixo da superfície. $\mathrm{O}$ vapor d'água alcança a superfície por difusão molecular e por fluxo de massa, causado pela flutuação da pressão do ar (Jensen et al., 1990).

Para calcular a evaporação da água do solo, Ritchie (1972) estabeleceu os índices $\mathrm{U}$ e a. $\mathrm{O}$ primeiro refere-se à quantidade de água evaporada no primeiro estágio; portanto, depende das características do solo; já o segundo corresponde à taxa de evaporação da água do solo no segundo estágio. Quando medido em campo, o valor de U varia de aproximadamente $5 \mathrm{~mm}$, para solo arenoso, a $14 \mathrm{~mm}$, para solo de textura mais argilosa (Ritchie \& Jonhson, 1990).

Bond \& Willis (1970) estudaram a influência da demanda evaporativa na duração do primeiro estágio e na magnitude da evaporação acumulada. O experimento foi conduzido em laboratório, utilizando-se colunas com solo franco-arenoso. Os tratamentos constaram de seis demandas evaporativas, que variaram de 4,7 a 13,4 $\mathrm{mm} \mathrm{d}^{-1}$. Com o aumento da demanda evaporativa, a quantidade de água evaporada no primeiro estágio diminuiu; entretanto, a quantidade de água evaporada nos 25 dias seguintes, após ter cessado o primeiro estágio, aumentou com a elevação da demanda evaporativa. Quando esta é superior a $10 \mathrm{~mm} \mathrm{~d}^{-1}$, a duração do primeiro estágio é muito curta, isto é, de aproximadamente dois dias, enquanto para uma demanda de aproximadamente $1 \mathrm{~mm} \mathrm{~d}^{-1}$ a duração do primeiro estágio é de mais ou menos 50 dias, fato este constatado também por Hillel (1971).

Lascano \& van Bavel (1986) avaliaram um modelo de evaporação de água do solo. Para tanto, instalaram um experimento em campo com microlisímetros de pesagem, para três ciclos de secamento do solo. Para os dois primeiros ciclos, a evaporação decresceu de 8 para $0,7 \mathrm{~mm} \mathrm{~d}^{-1}$, porém no terceiro ciclo a taxa de evaporação permaneceu constante em $4 \mathrm{~mm} \mathrm{~d}^{-1}$, para os três primeiros dias e depois decresceu para $0,4 \mathrm{~mm} \mathrm{~d}^{-1}$.

O tempo de exposição do resíduo da cultura no campo pode influenciar a taxa de cobertura do solo e, conseqüente- mente, a taxa de evaporação. Com o objetivo de quantificar o efeito do tempo de exposição do resíduo e sua disposição no campo, Sauer et al. (1996) avaliaram o efeito da evaporação da água do solo, nas seguintes condições: solo descoberto e solos com cobertura de resíduos frescos, resíduos deixados no tempo e resíduos deixados no tempo com uma faixa de $0,15 \mathrm{~m}$ de solo descoberto. A evaporação ocorrida no tratamento com solo sem cobertura foi de $9,97 \mathrm{~mm}$, em $96 \mathrm{~h}$, enquanto no tratamento com cobertura de resíduos a evaporação decresceu para $5,76 \mathrm{~mm}$. A evaporação média para o solo com cobertura foi de 1,33 a 1,4 $\mathrm{mm} \mathrm{d}^{-1}$. Os tratamentos com resíduos reduziram a evaporação de 34 a 50\%, com a faixa de valores refletindo diferentes espessuras das camadas de resíduos e disposição no campo. O tratamento com resíduos frescos apresentou maior espessura e, conseqüentemente, maior resistência de condutância de vapor. $\mathrm{O}$ tratamento com faixas de solo descoberto foi somente $7 \%$ superior ao tratamento com resíduo deixado no tempo.

As opções de manejo de resíduos, são: remover o resíduo e utilizá-lo com ou sem cortes ou incorporá-lo ao solo. A evaporação da água do solo com resíduos na superfície é bastante estudada, mas informações a respeito do efeito de resíduos cortados e incorporados ao solo na taxa de evaporação da água, particularmente relacionado ao tipo de solo e à taxa de evaporação, são incipientes. Considerando o exposto, Prihar et al. (1996) estudaram o efeito de resíduos da cultura do trigo, utilizados de várias maneiras, nas perdas por evaporação de água em colunas de solo, para três tipos de solos e dois regimes de evaporação. Os valores de U e a da equação de Ritchie foram obtidos. O valor de $U$ foi independente da taxa de resíduo, mas bastante afetado pelo tipo de solo, enquanto os valores de a decresceram com as taxas de resíduo e de evaporação e com a textura do solo.

O sistema de plantio direto em uso há vários anos no Brasil, vem sendo implementado em grande escala. Na safra 1999/2000, foram plantados aproximadamente 13 milhões de hectares em plantio direto. Este crescimento acentuado se deve a vários aspectos: importância econômica para os produtores e efeitos benéficos sobre as propriedades do solo, com o maior controle da erosão, a redução das perdas de água por escoamento superficial e o conseqüente aumento da disponibilidade hídrica para as culturas.

Com objetivo de auxiliar o manejo de água em sistema de plantio direto irrigado, desenvolveu-se a pesquisa com o propósito de analisar a influência dos resíduos de culturas do milho e do trigo nas fases de evaporação da água do solo, para duas classes texturais de solo.

\section{MATERIAL E MÉTODOS}

O experimento foi realizado no Laboratório de Hidráulica do Departamento de Engenharia Agrícola, pertencente à Universidade Federal de Viçosa, MG. As coordenadas geográficas locais são $20^{\circ} 45^{\prime} \mathrm{S}$, longitude $42^{\circ} 51^{\prime} \mathrm{W}$ e altitude de $651 \mathrm{~m}$.

As colunas de solo foram construídas com $45 \mathrm{~cm}$ de altura, utilizando-se tubos de PVC com $20 \mathrm{~cm}$ de diâmetro 
Tabela 1. Análise granulométrica

\begin{tabular}{ccccc}
\hline Solo & Areia Grossa (\%) & Areia Fina (\%) & Silte (\%) & Argila (\%) \\
\hline Areia franca & 25 & 59 & 11 & 5 \\
Muito argiloso & 6 & 3 & 15 & 76 \\
\hline
\end{tabular}

nominal. As colunas foram perfuradas na base para possibilitar a drenagem da água do solo. Construíram-se 39 colunas de PVC para a realização do experimento, sendo três sem perfurações na base; depois de construídas, cada coluna foi pesada sem solo, numa balança com capacidade mínima de $50 \mathrm{~g}$, máxima de $32.100 \mathrm{~g}$ e precisão de $1 \mathrm{~g}$.

No experimento foram utilizadas duas classes texturais de solo, um procedente de Janaúba, MG (Projeto Gorutuba, pertencente à CODESVAF - Companhia de Desenvolvimento do Vale do São Francisco) e o outro da Estação Experimental de Coimbra, MG (pertencente à Universidade Federal de Viçosa). Os solos foram destorroados, peneirados e secados ao ar, antes de serem colocados dentro das colunas. Os dois solos utilizados foram classificados, de acordo com sua textura, como muito argiloso e areia franca, cujas composições granulométricas estão apresentadas na Tabela 1. Os solos foram colocados nas colunas em camadas e, elas foram vibradas manualmente, para acondicionamento. Após o preenchimento das colunas, realizou-se outra pesagem, objetivando-se determinar o peso das colunas com solo, para efetuar o cálculo da densidade global média de cada solo.

A densidade global média do solo muito argiloso foi de 0,98 e a do solo areia-franca, de $1,19 \mathrm{~kg} \mathrm{dm}^{-3}$. As curvas de retenção da água no solo estão apresentadas na Figura 1.

Cada fileira constou de 13 colunas: 12 colunas foram preenchidas com solo (seis contendo solo muito argiloso e as outras seis, solo areia franca) e um recipiente com água, para determinação da demanda evaporativa.

Visando promover a evaporação nas superfícies dos solos e da água, construíram-se três suportes para lâmpadas. Cada suporte tinha $7 \mathrm{~m}$ de comprimento e 15 bocais, com lâmpadas de mesma potência; 13 para evaporar água e dois dispostos nas extremidades para uniformizar a demanda atmosférica naquelas colunas de solo das extremidades. Foi adotado um espaçamento de $0,5 \mathrm{~m}$ entre as lâmpadas e uma distância de $1,0 \mathrm{~m}$ entre as fileiras. Sobre cada uma das fileiras de colu-

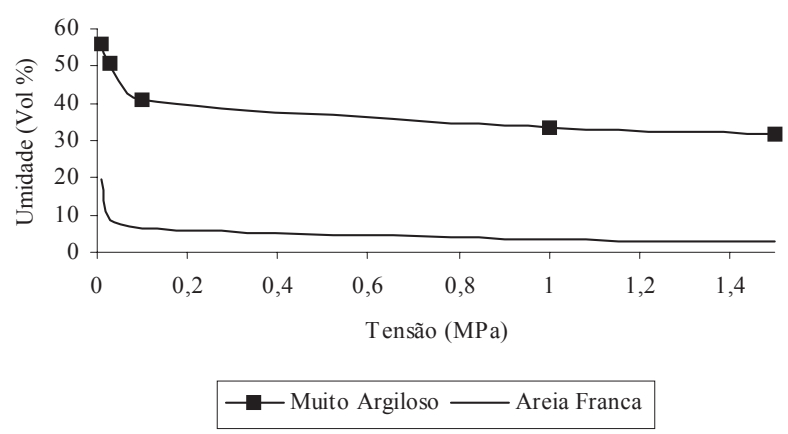

Figura 1. Curvas de retenção para duas classes de solo: areia franca e muito argiloso

R. Bras. Eng. Agríc. Ambiental, v.10, n.1, p.104-111, 2006. nas posicionou-se um suporte no qual cada lâmpada foi colocada acima do centro de cada coluna. O bocal foi instalado na estrutura, distando $57 \mathrm{~cm}$ do piso, de modo que as lâmpadas distassem $10 \mathrm{~cm}$ da superfície evaporante. As demandas evaporativas de 3, 6 e $8 \mathrm{~mm} \mathrm{~d}^{-1}$ para o experimento com resíduos do milho e 3, 5,2 e 7 para o experimento com resíduos do trigo foram obtidas ao se utilizar lâmpadas com 40, 100 e $150 \mathrm{~W}$ de potência. O sistema era acionado por um temporizador, que permitia que as lâmpadas permanecessem acessas $12 \mathrm{~h}$, durante o dia, e fossem desligadas à noite.

\section{Delineamento experimental}

Utilizaram-se resíduos de duas culturas, tendo os dados sido coletados para cada uma das culturas, em períodos distintos. Os dados foram coletados para experimento com resíduos da cultura do milho e do trigo, nos períodos de 29 de março a 25 de abril e de 3 a 29 de maio de 2000, respectivamente.

$\mathrm{O}$ experimento foi em fatorial de $3 \times 3 \times 2$, cujos tratamentos se constituíam de três demandas evaporativas, três taxas de resíduo cultural e dois tipos de solo. O delineamento experimental foi em blocos casualisados, com duas repetições e as colunas distribuídas ao acaso, de modo que seu centro estivesse situado abaixo da respectiva lâmpada incandescente.

Para definição das taxas de resíduo considerou-se uma produtividade média para cultura do milho produzida em sistema irrigado, levando-se em conta que a cultura do milho produz, em média, $10.000 \mathrm{~kg} \mathrm{ha}^{-1}$ de resíduos e a do trigo $7.000 \mathrm{~kg} \mathrm{ha}^{-1}$, cujo valor médio depende de muitos fatores, como genéticos, edáficos, práticas culturais e climáticos.

Utilizaram-se, no experimento, 50 e $100 \%$ da quantidade de resíduos das culturas. Em condições experimentais torna-se difícil trabalhar com quantidades de resíduos da ordem de $\mathrm{t} \mathrm{ha}^{-1}$; entretanto, com o valor da área de seção transversal das colunas de PVC $\left(314,16 \mathrm{~cm}^{2}\right)$, pode-se converter a quantidade de resíduos existentes em 1 ha em gramas por coluna. Para as culturas do milho obtiveram-se 15,7 e 31,4 g de resíduos por coluna e, do trigo, 11,5 e 22,0 , respectivamente, o que corresponde a 50 e $100 \%$ da quantidade da cobertura de resíduos disposta sobre o solo.

Antes de serem colocados nas colunas, os resíduos foram dispostos na plataforma de uma colheitadeira, para se obter as condições de campo e, depois, distribuídos em suas superfícies de modo uniforme, recobrindo igualmente os solos. As superfícies dos solos para os tratamentos com e sem resíduos se situaram $2 \mathrm{~cm}$ abaixo da borda da coluna de PVC; em seguida, procedeu-se à saturação das 36 colunas de solo, que foram tapadas com plástico; o plástico foi utilizado para não permitir perdas por evaporação, e deixadas em repouso por cinco dias, de modo que a água excedente fosse drenada. No momento da saturação os tratamentos sem resíduo na superfície, foram protegidos com um disco de feltro, com o objetivo de reduzir o impacto direto da água o que, conseqüentemente, causaria desprendimento de argila e ocasionaria o selamento do solo.

Decorrido o período de drenagem acionou-se o sistema de lâmpadas, que permaneciam em funcionamento durante $12 \mathrm{~h}$, visando simular o fotoperíodo. 


\section{Obtenção dos dados}

A coleta de dados foi realizada durante o período de 28 dias. Com a finalidade de se obter maior regularidade e precisão nos resultados, fixou-se um horário para a coleta de dados $(8 \mathrm{~h})$. Diariamente, cada coluna de solo foi pesada individualmente, numa balança com precisão de 1,0 g, e nas colunas destinadas à determinação das demandas evaporativas realizou-se a reposição da água evaporada. Para manter a regularidade nos resultados estabeleceu-se uma seqüência para as pesagens.

\section{Aplicação de lâmina d'água simulando uma irrigação ou precipitação pluvial}

Visando estudar o comportamento dos distintos tratamentos perante a condição de simulação de irrigação, no $21^{\circ}$ dia, aplicaram-se lâminas d'água nas superfícies das colunas de solo. As colunas de solo com e sem resíduos da cultura do milho receberam lâminas d'água de $20 \mathrm{~mm}$, isto é, um volume de $628 \mathrm{~mL}$. No tratamento com e sem resíduos da cultura do trigo, as colunas de solo receberam lâminas d'água de 10 e $20 \mathrm{~mm}$, o que corresponde ao volume de 314 e $628 \mathrm{~mL}$, respectivamente.

\section{Medição da temperatura do solo}

Para obtenção da temperatura do solo foram construídas duas colunas de PVC, com as mesmas características das utilizadas no experimento descrito anteriormente. Termopares foram inseridos em orifícios perpendiculares à parede da coluna de PVC, até o centro desta, a distâncias de 1, 3, 5, 10, 20 e $30 \mathrm{~cm}$ da superfície do solo sem resíduos. Cada coluna foi preenchida com uma classe de solo, cujo acondicionamento seguiu o mesmo procedimento das demais colunas. Logo após, os solos foram saturados e cobertos com plástico. Depois de cinco dias de drenagem as colunas de solo foram submetidas a uma demanda evaporativa de aproximadamente $8 \mathrm{~mm} \mathrm{~d}^{-1}$.

A aquisição dos dados de temperatura foi realizada automaticamente, por meio de uma aquisidora de dados acoplada a um computador. A temperatura foi medida em intervalos de $1 \mathrm{~h}$, em um período de $24 \mathrm{~h}$; em seguida, o sistema foi desligado durante $24 \mathrm{~h}$, e religado.

\section{Umidades dos solos nas colunas, no primeiro dia de pesagem}

Depois de se preencher as colunas com solo secado ao ar, elas foram pesadas. Instalado o experimento e após cinco dias da saturação das colunas de solo, iniciaram-se as pesagens. Com o peso de cada coluna no primeiro dia do início das pesagens para cada período de coleta de dados, determinouse a umidade em cada coluna pelas diferenças de peso das colunas sem solo, do solo secado ao ar e do peso desta no dia do início da evaporação da água do solo.

\section{RESULTADOS E DISCUSSÃO}

\section{Experimento com resíduos da cultura do milho}

Demanda evaporativa de $8 \mathbf{~ m m ~ d}^{-1}$. A evaporação da água do solo ocorrida no tratamento de demanda evaporati- va de $8 \mathrm{~mm} \mathrm{~d}^{-1}$, mostrou-se distinta para solos areia franca e muito argiloso, sem resíduos na superfície. Em solo areia franca, para os primeiros dias a evaporação foi superior à ocorrida em solo muito argiloso. Neste, a evaporação decresceu acentuadamente nos primeiros dias, enquanto para o solo areia franca esta se manteve em níveis elevados até o quinto dia (Figura 2), quando comparada com a demanda evaporativa, e então ocorreu redução acentuada. A evaporação da água no solo areia franca foi superior à do solo muito argiloso, até o $15^{\circ}$ dia, mas a partir deste dia ocorreu o inverso. Após dois dias do início da evaporação, o solo muito argiloso, passou a apresentar fendas que promoveram, possivelmente, a redução da evaporação da água do solo. Os dois solos permaneceram no primeiro estágio de evaporação nos primeiros três dias, em que esta depende somente da demanda evaporativa; após este período, a evaporação da água do solo passou para o segundo estágio, em que ela depende das características hidráulicas do solo.

A.

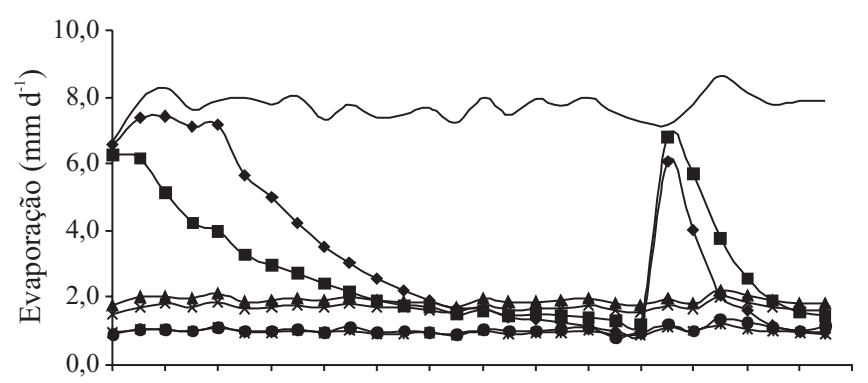

B.

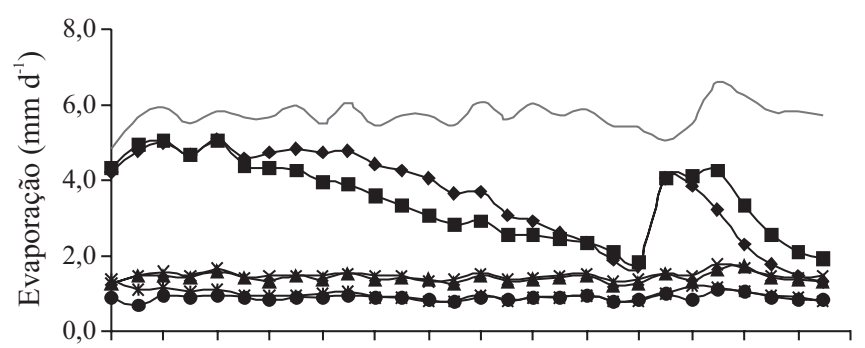

C.

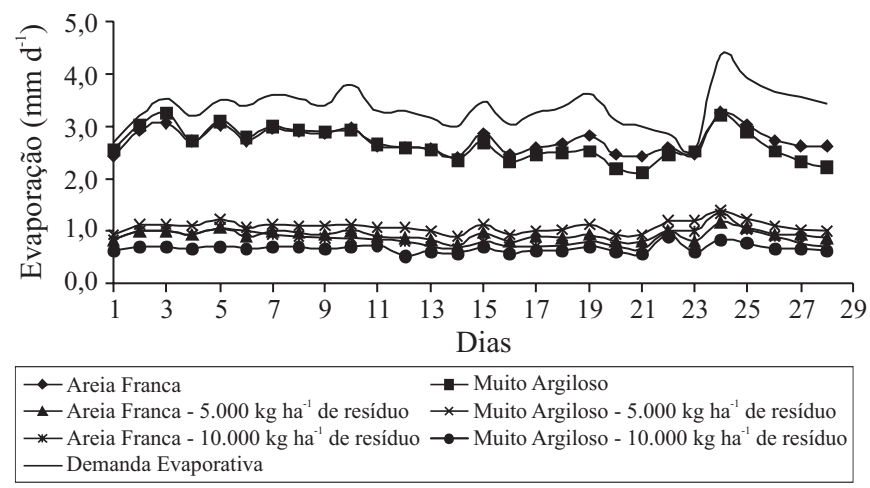

Figura 2. Evaporação da água do solo sem e com resíduos da cultura do milho sobre a sua superfície, em colunas de PVC, para uma demanda evaporativa em torno de $8 \mathrm{~mm} \mathrm{~d}^{-1}(\mathrm{~A})$, demanda evaporativa em torno de $6 \mathrm{~mm} \mathrm{~d}^{-1}$ (B) e demanda evaporativa em torno de $3 \mathrm{~mm} \mathrm{~d}^{-1}$ (C) 
A temperatura do solo elevou-se com o decréscimo de sua umidade, tendo a temperatura máxima para o solo muito argiloso sido de $54{ }^{\circ} \mathrm{C}$ e para areia franca de $42,7{ }^{\circ} \mathrm{C}$, para a profundidade de $1 \mathrm{~cm}$; para as profundidades de $3,5 \mathrm{e}$ $10 \mathrm{~cm}$, as diferenças de temperatura foram de aproximadamente $3{ }^{\circ} \mathrm{C}$; para as profundidades de 20 e $30 \mathrm{~cm}$, as temperaturas do solo areia franca foram superiores às do muito argiloso, em aproximadamente $1{ }^{\circ} \mathrm{C}$. A baixa umidade na superfície solo fez com que a transferência de água das camadas abaixo da superfície para atmosfera se processe por difusão de vapor, o que ocorreu no solo muito argiloso, desde o segundo dia do início do processo de evaporação.

No vigésimo primeiro dia simulou-se uma irrigação aplicando-se uma lâmina d'água de $20 \mathrm{~mm}$ em todos os tratamentos. Nos tratamentos com $10.000 \mathrm{~kg} \mathrm{ha}^{-1}$ de resíduos, para os solos areia franca e muito argiloso ocorreu drenagem nas colunas de solo; portanto, os dados foram descartados para este dia. Para os tratamentos com $5.000 \mathrm{~kg} \mathrm{ha}^{-1} \mathrm{de}$ resíduos não ocorreu drenagem, e após a aplicação da lâmina d'água se constatou aumento significativo da evaporação, como aconteceu para os solos sem resíduos, o que pode ser observado na Figura 2 A, pois os valores da evaporação foram próximos aos do início do processo em que o solo foi saturado; no entanto, a evaporação do solo muito argiloso foi superior à do solo areia franca, situação esta distinta do processo no início, quando o solo estava saturado.

A redução na taxa de evaporação da água do solo para a demanda evaporativa de $8 \mathrm{~mm} \mathrm{~d}^{-1}$ (Figura 2A), ocorrida nos primeiros dias, também foi observada por Lascano \& van Bavel (1986).

A evaporação nos tratamentos sem resíduos para a demanda evaporativa de $8 \mathrm{~mm} \mathrm{~d}^{-1}$, foi superior à do tratamento com $5.000 \mathrm{~kg} \mathrm{ha}^{-1}$ de resíduos até o $11^{\circ}$ dia, a partir deste dia, a evaporação do tratamento sem resíduo apresentou valores inferiores.

Os valores de evaporação da água do solo plotados nas Figuras 3(A, B, C) e 4(A, B, C) foram normalizados em relação à demanda evaporativa medida na coluna de PVC com água. Observa-se, na Figura 3A que a mudança na taxa de evaporação da água do solo é muito suave para determinar com clareza o término da primeira fase de evaporação. Para os tratamentos com resíduos não se observou mudança brusca na taxa de evaporação da água do solo, não ocorrendo a mudança de estágio de evaporação, resultados estes concordantes com Bonds \& Willis (1970) e Reichardt (1968).

Demanda evaporativa de $6 \mathbf{~ m m ~ d}^{-1}$ : A evaporação da água do solo para demanda evaporativa de $6 \mathrm{~mm} \mathrm{~d}^{-1}$ (Figura $3 \mathrm{~B}$ ) apresentou diferenças no comportamento, quando comparada com a demanda de $8 \mathrm{~mm} \mathrm{~d}^{-1}$ (Figura 2A). No período inicial as evaporações ocorridas nos dois solos foram praticamente iguais até o sexto dia, porém a partir deste dia a evaporação da água no solo areia franca superou a evaporação no solo muito argiloso, até o $20^{\circ}$ dia, enquanto para a demanda evaporativa de $8 \mathrm{~mm} \mathrm{~d}^{-1}$ a evaporação no solo areia franca foi superior à do solo muito argiloso (Figura 2A). A evaporação dos tratamentos sem resíduos foi superior à do tratamento com $5.000 \mathrm{~kg} \mathrm{ha}^{-1} \mathrm{de}$ resíduos, para todo o período.
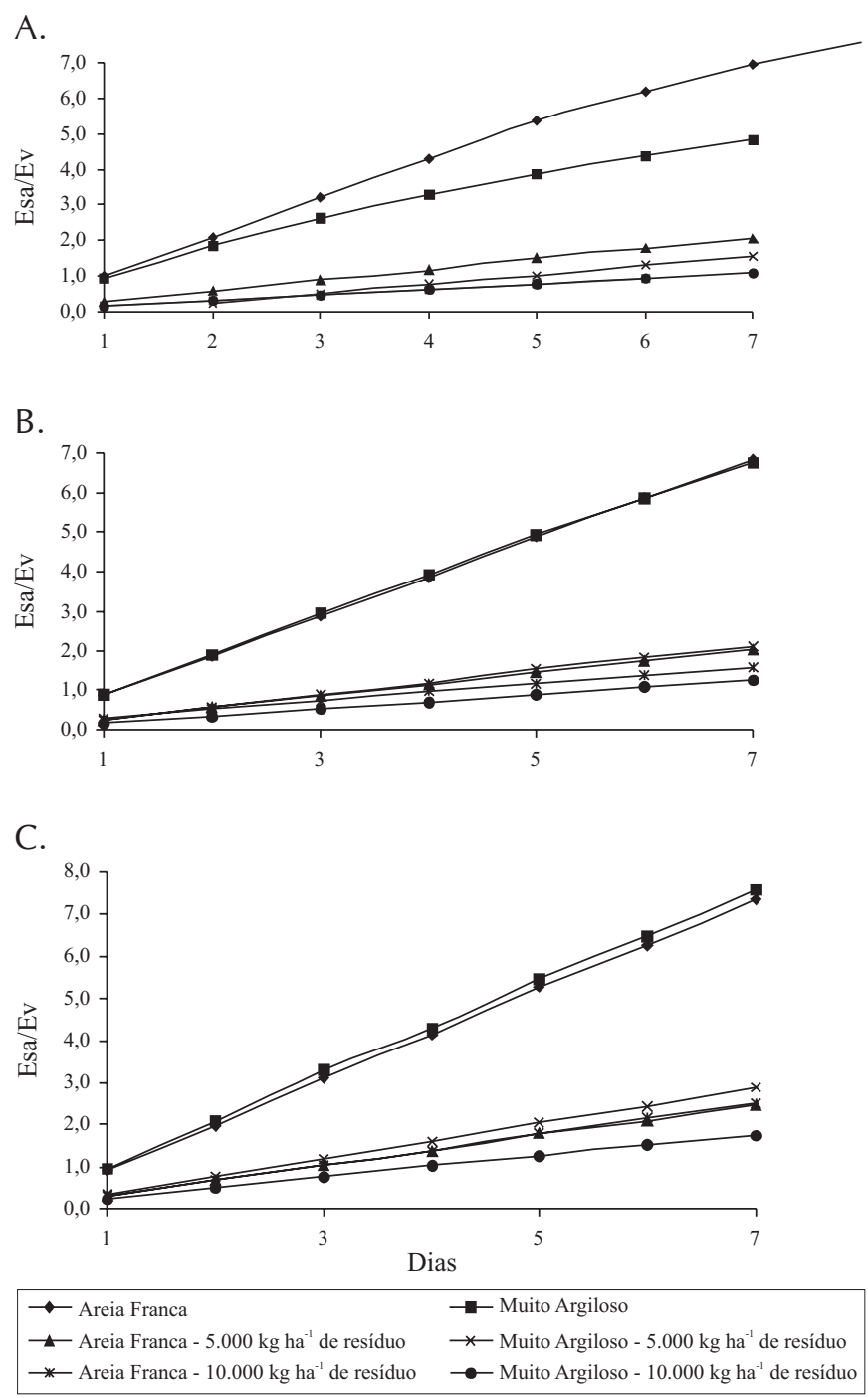

Figura 3. Evaporação acumulada da água do solo sem e com resíduos da cultura do milho sobre sua superfície (Esa/ev), normalizada em relação à evaporação na coluna com água, para uma demanda evaporativa em torno de $8 \mathrm{~mm} \mathrm{~d}^{-1}(\mathrm{~A})$, demanda evaporativa em torno de $6 \mathrm{~mm} \mathrm{~d}^{-1}(\mathrm{~B})$ e demanda evaporativa em torno de $3 \mathrm{~mm} \mathrm{~d}^{-1}(\mathrm{C})$

Pode-se observar, na Figura 3B, que não ocorreu mudança de fase para os tratamentos quando a demanda evaporativa foi de $6 \mathrm{~mm} \mathrm{~d}^{-1}$, fato este que não aconteceu para demanda de $8 \mathrm{~mm} \mathrm{~d}^{-1}$ para solos descobertos.

Após a aplicação da lâmina d'água de $20 \mathrm{~mm}$ no $21^{\circ}$ dia, a evaporação do solo muito argiloso foi superior à do solo areia franca, o que contrasta com o período inicial do experimento, quando o solo foi saturado e deixado drenar por cinco dias, tendo o solo areia franca apresentado evaporação superior.

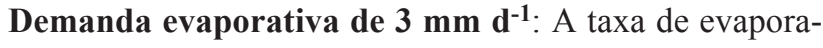
ção nos tratamentos com solo descoberto foi aproximadamente três vezes à dos tratamentos com cobertura de resíduos. $\mathrm{O}$ tratamento com $10.000 \mathrm{~kg} \mathrm{ha}^{-1}$ de resíduos e solo areia franca apresentou valores superiores aos dos demais tratamentos com resíduos, nos primeiros dias do experimento, pelo fato de, nessas colunas de solo, a drenagem não ter cessado após os cinco dias da saturação. 
A taxa de evaporação da água do solo descoberto para demandas evaporativas em torno de $3 \mathrm{~mm} \mathrm{~d}^{-1}$, aproximouse do valor da demanda evaporativa (Figura 2C).

Para a demanda evaporativa de $3 \mathrm{~mm} \mathrm{~d}^{-1}$ (Figura 3C), observou-se que a evaporação da água no solo permaneceu no primeiro estágio de evaporação, no período de coleta de dados do experimento, que foi de 21 dias; esses resultados são concordantes com os de Bonds \& Willis (1970) e Reichardt (1968).

Analisando-se os dados da Tabela 2, nota-se que a demanda evaporativa influenciou a quantidade de água evaporada em cada tratamento, levando-se em conta o solo descoberto e a quantidade de água evaporada nas colunas de solo, nos primeiros sete dias, considerando-se sistema de produção irrigado com turno de rega de sete dias No tratamento com demanda evaporativa de $8 \mathrm{~mm} \mathrm{~d}^{-1}$, constatou-se quantidade de água evaporada, quando comparada com a do tratamento com demanda evaporativa de $6 \mathrm{~mm} \mathrm{~d}^{-1}$.

Considerando-se o tratamento com $5.000 \mathrm{~kg} \mathrm{ha}^{-1}$ de resíduos da cultura, observou-se que a demanda evaporativa influenciou a quantidade de água evaporada durante o período do experimento. A quantidade de água evaporada nos tratamentos com demandas evaporativas de 6 e $3 \mathrm{~mm} \mathrm{~d}^{-1}$, correspondeu a 71 e $47 \%$, respectivamente, da quantidade evaporada no tratamento com a demanda de $8 \mathrm{~mm} \mathrm{~d}^{-1}$, para o solo areia franca (Tabela 3 ).

Enfatizando-se o tratamento com $10.000 \mathrm{~kg} \mathrm{ha}^{-1}$ de resíduos da cultura, verificou-se que a demanda evaporativa não influenciou a quantidade de água evaporada durante o período do experimento, para as demandas evaporativas de 8 e $6 \mathrm{~mm} \mathrm{~d}^{-1}$. Para a demanda evaporativa de $3 \mathrm{~mm} \mathrm{~d}^{-1}$, para o solo areia franca, a quantidade de água evaporada foi superior à do tratamento com solo muito argiloso, em razão de nos primeiros dias de pesagem nas colunas de solo areia franca a drenagem do solo ter sido pequena mas a drenagem continuava ocorrendo, visto que a parte externa do fundo das colunas estava úmida.

Segundo o conceito U, estabelecido por Ritchie (1972), a evaporação da água do solo se processa no primeiro estágio, até atingir o valor de $\mathrm{U}$ para determinado solo, mas para a demanda evaporativa de $3 \mathrm{~mm} \mathrm{~d}^{-1}$, não se observou a mudança de estágio e permaneceu no primeiro estágio por todo o período de coleta de dados, cuja duração foi de 21 dias (Figuras 2C e 4B). A lâmina d'água evaporada no período para as duas classes texturais de solos, no tratamento com solo descoberto muito argiloso e areia franca, foi de 56,4 e $57,2 \mathrm{~mm}$, respectivamente, para a demanda de $3 \mathrm{~mm} \mathrm{~d}^{-1}$ (Tabela 3).

Prihar et al. (1996) encontraram que o valor de $U$ foi independente da quantidade de resíduos porém para o experimento em questão, nas evaporações da água do solo nos tratamentos com resíduos, o valor de U não foi atingido, pois não ocorreu mudança de fase.

Realizou-se análise estatística dos valores da lâmina d'água evaporada em cada tratamento em 21 dias, para as três demandas evaporativas e se empregou o teste de Tukey a nível de 5\% probabilidade (Tabelas 4 e 5). Observa-se, na Tabela 4, que houve diferença significativa entre as taxas de resíduos, mas não ocorreu diferença entre as duas classes de solos, mas para taxa de resíduo de $5.000 \mathrm{~kg} \mathrm{ha}^{-1}$ muito argiloso e $10.000 \mathrm{~kg} \mathrm{ha}^{-1}$ areia franca não houve diferença significativa a nível de $5 \%$ de probabilidade.

Tabela 3. Lâmina d'água evaporada em cada tratamento em 21 dias, em experimento com resíduos da cultura do milho

\begin{tabular}{|c|c|c|c|}
\hline \multirow{2}{*}{$\begin{array}{c}\text { Tratamentos } \\
\text { Solos e Taxas de Resíduos }\end{array}$} & \multicolumn{3}{|c|}{$\begin{array}{c}\text { Demanda Evaporativa } \\
\left(\mathrm{mm} \mathrm{d}^{-1}\right)\end{array}$} \\
\hline & 8 & 6 & 3 \\
\hline Areia Franca com resíduos & 74,2 & 82,0 & 57,2 \\
\hline Muito Argiloso & 56,4 & 74,2 & 56,4 \\
\hline Areia Franca com $5.000 \mathrm{~kg} \mathrm{ha}^{-1}$ de resíduos & 40,2 & 28,9 & 19,0 \\
\hline Muito Argiloso com $5.000 \mathrm{~kg} \mathrm{ha}^{-1}$ de resíduos & 35,7 & 30,1 & 22,2 \\
\hline Areia Franca com $10.000 \mathrm{~kg} \mathrm{ha}^{-1}$ de resíduos & 20,4 & 19,8 & 18,6 \\
\hline Muito Argiloso com $10.000 \mathrm{~kg} \mathrm{ha}^{-1}$ de resíduos & 21,1 & 18,1 & 13,6 \\
\hline Demanda evaporativa & 160,8 & 119,1 & 69,6 \\
\hline
\end{tabular}

Tabela 4. Análise estatística do tratamento quantidade de resíduo

\begin{tabular}{lcccc}
\hline \multicolumn{1}{c}{ Tratamentos } & Dados & \multicolumn{2}{c}{ Médias } \\
Areia Franca & 6 & 63,60 & A \\
Muito Argiloso & 6 & 60,59 & A \\
Areia Franca com $5.000 \mathrm{~kg} \mathrm{ha}^{-1}$ de resíduos & 6 & 32,45 & B \\
Muito Argiloso com $5.000 \mathrm{~kg} \mathrm{ha}^{-1}$ de resíduos & 6 & 29,82 & B \\
Areia Franca com $10.000 \mathrm{~kg} \mathrm{ha}^{-1}$ de resíduos & 6 & 25,69 & B \\
Muito Argiloso com $10.000 \mathrm{~kg} \mathrm{ha}^{-1}$ de resíduos & 6 & 20,92 & B \\
\hline
\end{tabular}

Tabela 2. Taxas médias de evaporação, para os primeiros sete dias nos tratamentos, com relação às demandas evaporativas

\begin{tabular}{|c|c|c|c|c|c|c|}
\hline \multirow{2}{*}{ Tratamentos } & \multicolumn{6}{|c|}{ Demanda Evaporativa $\left(\mathrm{mm} \mathrm{d}^{-1}\right)$} \\
\hline & 8 & 6 & 3 & 8 & 6 & 3 \\
\hline Solos e Taxas de Resíduos & \multicolumn{3}{|c|}{ Taxas (\%) } & \multicolumn{3}{|c|}{ Taxa de Evaporação $\left(\mathrm{mm} \mathrm{d}^{-1}\right)$} \\
\hline Areia franca sem resíduos & 85 & 85 & 86 & 6,6 & 4,7 & 2,8 \\
\hline Muito Argiloso sem resíduos & 59 & 84 & 88 & 4,6 & 4,7 & 2,9 \\
\hline Areia Franca com - $5.000 \mathrm{~kg} \mathrm{ha}^{-1}$ de resíduos & 25 & 25 & 29 & 2,0 & 1,4 & 1,0 \\
\hline Muito Argiloso com - $5.000 \mathrm{~kg} \mathrm{ha}^{-1}$ de resíduos & 22 & 26 & 33 & 1,7 & 1,5 & 1,1 \\
\hline Areia Franca - $10.000 \mathrm{~kg} \mathrm{ha}^{-1}$ de resíduos & 13 & 19 & 29 & 1,0 & 1,1 & 1,0 \\
\hline Muito Argiloso - $10.000 \mathrm{~kg} \mathrm{ha}^{-1}$ de resíduos & 13 & 15 & $21^{*}$ & 1,0 & 0,3 & 0,2 \\
\hline
\end{tabular}

* A drenagem não cessou após o início das pesagens 
Tabela 5. Análise estatística do tratamento demanda evaporativa

\begin{tabular}{cccc}
\hline \multicolumn{1}{c}{ Tratamentos } & Dados & \multicolumn{2}{c}{ Médias } \\
Demanda evaporativa de $8 \mathrm{~mm} \mathrm{~d}^{-1}$ & 12 & $44,43 \mathrm{~B} \mathrm{~A}$ & $\mathrm{~A}$ \\
Demanda evaporativa de $6 \mathrm{~mm} \mathrm{~d}^{-1}$ & 12 & $37,64 \mathrm{~B}$ & $\mathrm{~A}$ \\
Demanda evaporativa de $3 \mathrm{~mm} \mathrm{~d}^{-1}$ & 12 & $34,26 \mathrm{C}$ & $\mathrm{B}$ \\
\hline
\end{tabular}

\section{Experimento com resíduos da cultura do trigo}

Também como no tratamento com resíduos da cultura do milho e demanda de $8 \mathrm{~mm} \mathrm{~d}^{-1}$, foi difícil observar a mudança na taxa de evaporação da água do solo, mas se percebe, na Figura 4A, pequena mudança na inclinação das curvas de evaporação relativa da água do solo para o solo areia franca, a partir do quarto dia, e para a classe de solo muito argiloso, a partir do segundo dia. Para os tratamentos com resíduos não se observou mudança brusca na taxa de evaporação da água do solo, não ocorrendo, portanto, a mudança de estágio de evaporação, resultados estes também concordantes com os obtidos por Bonds \& Willis (1970) e Reichardt (1968).

Para o tratamento com resíduos de trigo e demanda evaporativa de 5,2 $\mathrm{mm} \mathrm{d}^{-1}$ verifica-se, média, na Figura 4B que nos tratamentos com solo descoberto a mudança na taxa de evaporação da água do solo, ao longo do período, apresenta pequena variação a partir do sexto dia, para os demais tratamentos com resíduos da cultura do trigo na superfície do solo, para as taxa de resíduos de 3.500 e $7.000 \mathrm{~kg} \mathrm{ha}^{-1}$, não ocorreram mudanças nas taxas de evaporação da água do solo, sem mudança de fase.

$\mathrm{Na}$ Figura 4C, relativa à demanda evaporativa de $3 \mathrm{~mm} \mathrm{~d}^{-1}$ observa-se, para todos os tratamentos, ausência mudanças na taxa de evaporação da água do solo, em que todos os tratamentos permaneceram na primeira fase de evaporação, não ocorrendo mudanças de fase.

As relações entre as taxas de evaporação para os tratamentos com as demandas evaporativas, estão apresentadas na Tabela 6, para período de sete dias inicais. As relações dos tratamentos com solo descoberto e resíduos da cultura do trigo com a demanda evaporativa,foram aproximadamente iguais para os dados coletados com resíduos da cultura do milho (Tabela 2).

A redução na quantidade e na taxa da água evaporada foi acentuada com a adição das duas taxas de resíduo sobre a superfície do solo (Tabelas 2 e 6). A redução na demanda
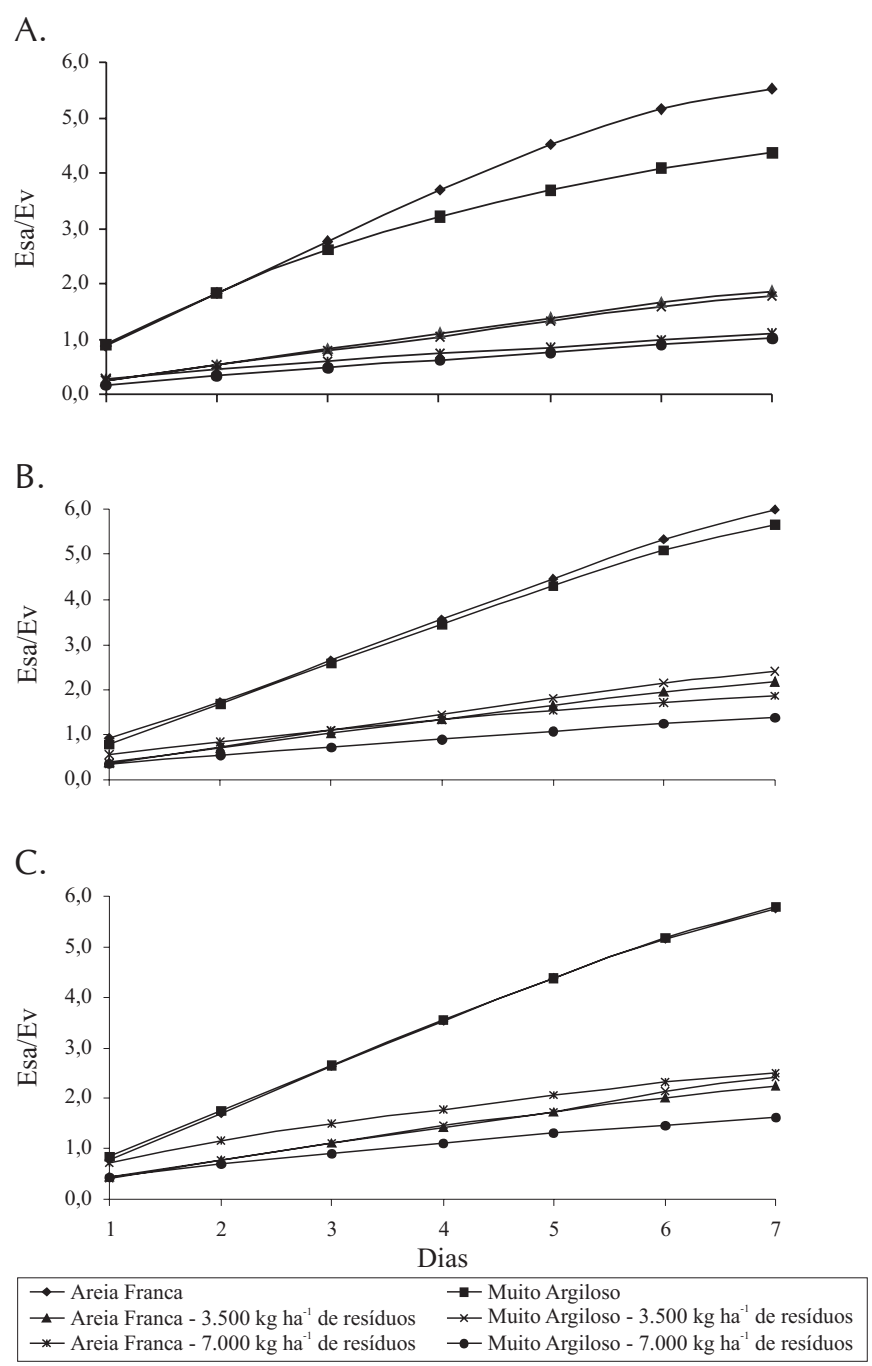

Figura 4. Evaporação acumulada da água do solo sem e com resíduos da cultura do trigo sobre sua superfície (Esa/ev), normalizada em relação à evaporação na coluna com água, para uma demanda evaporativa em torno de $7 \mathrm{~mm} \mathrm{~d}^{-1}(\mathrm{~A})$, demanda evaporativa em torno de $5,2 \mathrm{~mm} \mathrm{~d}^{-1}$ (B) e demanda evaporativa em torno de $3 \mathrm{~mm} \mathrm{~d}^{-1}(\mathrm{C})$

evaporativa para os tratamentos com $100 \%$ da matéria seca, promoveu pequena redução na evaporação da água do solo, para essas condições.

As quantidades de água evaporada nos tratamentos com as duas taxas de resíduos, 50 e 100\% da produção de matéria seca, para as culturas do milho e do trigo, a despeito da

Tabela 6. Taxas médias de evaporação para os primeiros sete dias, nos tratamentos, com relação às demandas evaporativas

\begin{tabular}{|c|c|c|c|c|c|c|}
\hline \multirow{2}{*}{ Tratamentos } & \multicolumn{6}{|c|}{ Demanda Evaporativa $\left(\mathrm{mm} \mathrm{d}^{-1}\right)$} \\
\hline & 7 & 5,2 & 3 & 7 & 5,2 & 3 \\
\hline Solos e Taxas de Resíduos & \multicolumn{3}{|c|}{ Taxas (\%) } & \multicolumn{3}{|c|}{ Taxa de Evaporação $\left(\mathrm{mm} \mathrm{d}^{-1}\right)$} \\
\hline Areia franca sem resíduos & 79 & 79 & 84 & 5,7 & 4,1 & 2,5 \\
\hline Muito Argiloso sem resíduos & 63 & 74 & 85 & 4,6 & 3,9 & 2,5 \\
\hline Areia Franca $-3.500 \mathrm{~kg} \mathrm{ha}^{-1}$ de resíduos & 28 & 29 & 33 & 2,0 & 1,5 & 1,0 \\
\hline Muito Argiloso com $3.500 \mathrm{~kg} \mathrm{ha}^{-1}$ de resíduos & 25 & 32 & 35 & 1,8 & 1,7 & 1,1 \\
\hline Areia Franca com $7.000 \mathrm{~kg} \mathrm{ha}^{-1}$ de resíduos & 17 & 24 & 37 & 1,2 & 1,3 & 1,1 \\
\hline Muito Argiloso com $7.000 \mathrm{~kg} \mathrm{ha}^{-1}$ de resíduos & 16 & 18 & 24 & 1,1 & 1,0 & 0,7 \\
\hline
\end{tabular}


Tabela 7. Lâmina d'água evaporada em cada tratamento em 21 dias, em experimento com resíduos da cultura do trigo

\begin{tabular}{lccc}
\hline \multicolumn{1}{c}{ Tratamentos } & \multicolumn{3}{c}{$\begin{array}{c}\text { Demanda Evaporativa } \\
\text { Solos e Taxas de Resíduos }\end{array}$} \\
\cline { 2 - 4 } & $\mathbf{7}$ & $\mathbf{5 , 2}$ & $\mathbf{3}$ \\
Areia Franca & 59,2 & 68,0 & 47,9 \\
Muito Argiloso & 54,7 & 59,0 & 46,9 \\
Areia Franca com $3.500 \mathrm{~kg} \mathrm{ha}^{-1}$ de resíduos & 38,0 & 28,4 & 18,5 \\
Muito Argiloso com $3.500 \mathrm{~kg} \mathrm{ha}^{-1}$ de resíduos & 35,2 & 32,0 & 22,8 \\
Areia Franca com7.000 $\mathrm{kg} \mathrm{ha}^{-1}$ de resíduos & 20,6 & 20,0 & 16,5 \\
Muito Argiloso com $7.000 \mathrm{~kg} \mathrm{ha}^{-1}$ de resíduos & 20,3 & 17,1 & 13,1 \\
Demanda evaporativa & 144,9 & 104,8 & 59,9 \\
\hline
\end{tabular}

pequena diferença entre as demandas evaporativas nos dois períodos de coleta de dados, foram mais ou menos iguais (Tabelas 3 e 7).

Realizou-se análise estatística dos valores da lâmina d'água evaporada em cada tratamento em 21 dias, para as três demandas evaporativas, utilizou-se o teste de Tukey a nível de $5 \%$ probabilidade (Tabelas 8 e 9). Como para a cultura do milho, observou-se haver diferenças siginificativas entre as taxas de resíduo mas não ocorreu diferenças entre as duas classes de solo (Tabela 8) para taxa de resíduo de $3.500 \mathrm{~kg} \mathrm{ha}^{-1}$ areia franca e $7.000 \mathrm{~kg} \mathrm{ha}^{-1}$ areia franca não ocorreu diferença significativa a nível de 5\% de probabilidade, fato este diferente do que se deu na cultura do milho.

Tabela 8. Análise estatística dos tratamentos quantidade de resíduo

\begin{tabular}{lccc}
\hline \multicolumn{1}{c}{ Tratamentos } & Dados & Médias & \\
Areia Franca & 6 & 55,83 & A \\
Muito Argiloso & 6 & 52,70 & A \\
Muito Argiloso com $3,500 \mathrm{~kg} \mathrm{ha}^{-1}$ de resíduos & 6 & 30,78 & B \\
Areia Franca com $3,500 \mathrm{~kg} \mathrm{ha}^{-1}$ de resíduos & 6 & 26,67 & B C \\
Areia Franca com $7.000 \mathrm{~kg} \mathrm{ha}^{-1}$ de resíduos & 6 & 18,97 & C D \\
Muito Argiloso com $7.000 \mathrm{~kg} \mathrm{ha}^{-1}$ de resíduos & 6 & 17,29 & D \\
\hline
\end{tabular}

Tabela 9. Análise estatística dos tratamentos quantidade de resíduo

\begin{tabular}{lccc}
\hline \multicolumn{1}{c}{ Tratamentos } & Dados & Médias & \\
Demanda evaporativa de $5,2 \mathrm{~mm} \mathrm{~d}^{-1}$ & 12 & 39,78 & A \\
Demanda evaporativa de $7 \mathrm{~mm} \mathrm{~d}^{-1}$ & 12 & 35,07 & A \\
Demanda evaporativa de $3 \mathrm{~mm} \mathrm{~d}^{-1}$ & 12 & 27,39 & B \\
\hline
\end{tabular}

\section{CONCLUSÕES}

1. A taxa de evaporação da água do solo descoberto apresentou comportamento distinto para as três demandas evaporativas utilizadas.

2. Para a demanda evaporativa de aproximadamente $3 \mathrm{~mm} \mathrm{~d}^{-1}$, o tratamento com solo descoberto permaneceu no primeiro estágio de evaporação, pelo período de 21 dias do experimento.
3. O conceito U, estabelecido por Ritchie (1972) para definir o final do primeiro estágio, não foi observado para as demandas evaporativas de 5,2 e $3 \mathrm{~mm} \mathrm{~d}^{-1}$. Para essas demandas, o solo permaneceu no primeiro estágio de evaporação durante o período de coleta de dados, ou seja, 21 dias.

4. Os tratamentos com resíduos da cultura do milho e do trigo para as taxas de 50 e $100 \%$ de matéria seca, permaneceram no primeiro estágio de evaporação, independente da demanda.

5. Para a taxa de resíduos de $100 \%$ da matéria seca, para as culturas do milho e do trigo, a demanda evaporativa teve pequena influência na redução na evaporação da água do solo que, em média, variou de $28 \%$ da evaporação ocorrida no tratamento com solo descoberto, e com coeficiente de variação de $18 \%$ para as duas classes de solo.

\section{LITERATURA CITADA}

Bond, J. J.; Willis, W. O. Soil water evaporation: first stage drying as influenced by surface residue and evaporation potential. Soil Science Society of America Journal, Madison, v.34, p.924-928, 1970.

Hillel, D. Soil and water: physical principles and processes. NewYork: Academic Press. 1971. 288p.

Jensen, M.; Burman, R. D.; Allen, R. G. Evapotranspiration and irrigation water requirements. New York: ASCE, 1990. 332p. Manuals and reports on engineering practice, 70

Lascano, R. J.; van Bavel, C. H. M. Simulation and measurement of evaporation from a bare soil. Soil Science Society of America Journal, Madison, v.50, p.1127-1133, 1986.

Prihar, S. S.; Jalota, S. K.; Steiner, J. L. Residue management for reducing evaporation in relation to soil type and evaporativity. Soil Use Management, Oxon; v.12, p.150-157, 1996.

Reichardt, K. Estudo do processo da evaporação da água do solo. Piracicaba: ESALQ-USP, 1968, 95p. Tese Livre Docência

Ritchie, J. T. Model for predicting evaporation from a row crop with incomplete cover. Water Resources Research, Washington, v.8, n.5, p.1204-1213, 1972.

Ritchie, J. T.; Jonhson, B. S. Soil and plant factors affecting evaporation In: Stewart, B. A.; Nielsen, D. R (ed.). Irrigation of agricultural crops. Madison: American Society of Agronomy, 1990. cap.13, p.363-39030, Agronomy Series 30

Sauer, T. J.; Hatfield, J. L.; Prueger, J. H. Corn residue age and placements effects evaporation and soil thermal regime. Soil Science Society of America Journal, Madison, v.60, p.15581564, 1996. 